\title{
1-Dimensional Chromatography
}

National Cancer Institute

\section{Source}

National Cancer Institute. 1-Dimensional Chromatography. NCI Thesaurus. Code C161589.

The use of a single chromatography-based technique to separate the various substances in a mixture. 